\title{
Baseline maritime aerosol: methodology to derive the optical thickness and scattering properties
}

\author{
Yoram J. Kaufman', Alexander Smirnov ${ }^{2}$, Brent N. Holben ${ }^{1}$ and Oleg Dubovik ${ }^{2}$
}

\begin{abstract}
Satellite Measurements of the global distribution of aerosol and their effect on climate should be viewed in respect to a baseline aerosol. In this concept, concentration of fine mode aerosol particles is elevated above the baseline by man-made activities (smoke or urban pollution), while coarse mode by natural processes (e.g. dust or sea-spray). Using 1-3 years of measurements in 10 stations of the Aerosol Robotic network (AERONET) we develop a methodology and derive the optical thickness and properties of this baseline aerosol for the Pacific and Atlantic Oceans. Defined as the median for periods of stable optical thickness (standard deviation < 0.02) during 2-6 days, the median baseline aerosol optical thickness over the Pacific Ocean is 0.052 at $500 \mathrm{~nm}$ with $\AA$ ngström exponent of 0.77 , and 0.071 and 1.1 respectively, over the Atlantic Ocean.
\end{abstract}

\section{Introduction}

The human induced changes in the aerosol concentration and properties, or the aerosol response to climate change (e.g. droughts producing fires and dust) should be measured relative to a "baseline aerosol" with minimal impact of manmade pollution or smoke aerosol or dust that is partially in response to land use change and climate driven droughts. How to define this baseline aerosol, so that it is both measurable and useful? Over the ocean aerosol is not necessary from maritime origin. There is a need to separate it from the baseline aerosol of marine origin, e.g. aerosol from oxidation of DMS and sea spray. Some residual, long lived, continental aerosol may also contribute/contaminate this value. Therefore the baseline aerosol is very broadly spread, resulting in smaller temporal variability than pollution, smoke aerosol or dust that originate from specific locations (e.g. city or dry lakebed) and are emitted and transported to the oceanic measuring site in a specific combination of meteorological conditions. Therefore, the baseline aerosol can be defined as the median aerosol for conditions with small temporal variations. Measurements of the baseline aerosol should help quantifying the contribution of natural and manmade sources to satellite or ground based measurements of aerosol [Jankowiak and Tanré, 1992; Husar et al., 1997; Kaufman et al., 1997; Mishchenko et al., 1999; Holben et al., 2001]. Model assessments of the aerosol forcing of climate can also use these results [e.g. Kiebl and Briegleb, 1993; Tegen et al., 1996; Hansen et al., 1997]. The baseline aerosol is derived from AERONET maritime measurements taken in the last 1-3 years. The AERONET network is described by Holben et al. [1998; 2001], climatology of maritime aerosol by Smirnov et al. [2001].

\section{Analysis}

The baseline aerosol is determined using time sequences measured in the AERONET sites. Example for two sites is given in Fig. 1. One site is in usually clean conditions in the middle of the Pacific Ocean - Lanai, and the second in the Atlantic Ocean, affected by pollution from North America and dust from Africa - Bermuda. The time series of the aerosol optical thickness at $500 \mathrm{~nm}, \tau_{500}$, and the Angström exponent, $\alpha$-variation between optical thickness at 440 and $870 \mathrm{~nm}: \alpha=\ln \left(\tau_{4} / \tau_{8}\right) / \ln (870 / 440)$ is plotted. The measurements are taken every 15 minutes, daily. They are cloud screened and quality assured [Smimov et al., 2000]; As expected, Fig. 1 shows that the conditions in the remote site of Lanai are stable while in Bermuda episodes of intrusion of pollution and dust are observed most of the time.
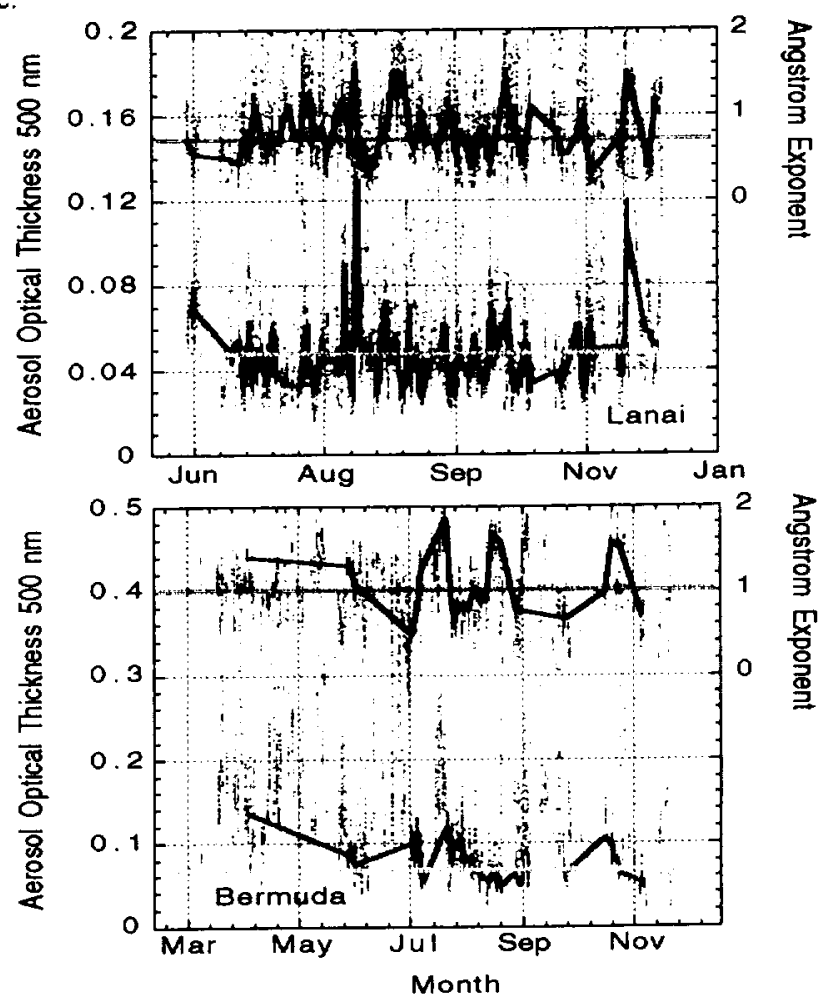

Fig. 1: Time sequence of the aerosol optical thickness (red) and Angstrom Exponent (blue) for Lanai (data from 1998) in the Pacific Ocean and Bermuda (1996) in the Atlantic Ocean. Dots are the individual measurements taken in 15 minutes intervals. Lines connect the medians for standard deviation $\Delta \tau<0.02$. The horizontal lines are the medians of the selected medians for the whole time series (see table 1).

To define the baseline aerosol in a consistent way for these diverse sites, we first compute the median of $\mathrm{N}$ consequent measurements. We repeat the calculations shifting each time by one measurement point (a running median). Two values of $\mathrm{N}$ are used for comparison: $\mathrm{N}=50$, that corresponds in average cloudy conditions to 2-3 days of

\footnotetext{
${ }^{1}$ NASA Goddard Space Flight Center, Greenbelt, MD 20771

2 Science Systems and Applications, Inc., Lanham, MD 20706
} 
measurements and $\mathrm{N}=100$ (4-5 days). Most high polluted or dusty conditions correspond to data sequences with high standard deviation of the optical thickness, $\Delta \tau>0.02$, and are excluded from the baseline statistics. A median is computed for the ensemble of the remaining medians. The use of medians rather than average excludes those rare cases of pollution or dust episodes that are stable during the $\mathrm{N}$ measurements and survived the first screening. This method results in a single annual value, with no seasonal or wind speed dependence. Table 1 summarizes the results for $\mathrm{N}=100$ for the 10 oceanic sites. The baseline aerosol over the Pacific Ocean is characterized by $\tau_{500}=0.052$ and $\alpha=0.77$ (calculated as weighted averages). Over the Atlantic Ocean the values are higher: $\tau_{300}=0.071$ and $\alpha=1.1$. Changing the number of elements in the running median from 100 to 50 increased the median optical thickness only by $\Delta \tau_{s 00} \sim 0.002$. Thus the results are robust against this choice of N. 14,000 and 3000 medians respectively for the Pacific and Atlantic oceans passed the criteria for $\mathrm{N}=100$ and were used in the baseline statistics $(20,000$ and 5000 respectively for $\mathrm{N}=50$ ). Increasing the threshold of standard deviation for the stability of the baseline from $\Delta \tau=0.02$ to 0.03 increases the derived baseline optical thickness by $\Delta \tau_{500} \sim 0.004$. If we would use averages instead of the medians, the baseline values would increase by 0.002 to 0.008 .

Table 1: The baseline aerosol optical thickness at $500 \mathrm{~nm}$, $\tau_{500}$, the total precipitable water vapor, $W V$, and the Angstrom exponent $\alpha$, derived as the median of an assemble of medians of 100 consecutive measurements with standard deviation in $\tau_{500}<0.02$.

\begin{tabular}{|c|c|c|c|c|}
\hline Location & $\begin{array}{c}\text { Median } \\
\tau_{s}\end{array}$ & WV & $\bar{\alpha}$ & $\begin{array}{l}\# \text { of } \\
\text { medians }\end{array}$ \\
\hline \multicolumn{5}{|c|}{ Atlantic Ocean } \\
\hline Ascension Island $8^{\circ} \mathrm{S} .15^{\circ} \mathrm{W}$ & 0.100 & 3.76 & 0.71 & 203 \\
\hline Cape Verde $17^{\circ} \mathrm{N} 23^{\circ} \mathrm{W}$ & 0.063 & 1.92 & 0.64 & 130 \\
\hline Dry Tortugas $25^{\circ} \mathrm{N} 83^{\circ} \mathrm{W}$ & 0.079 & 3.86 & 1.11 & 714 \\
\hline Bermuda $32^{\circ} \mathrm{N} 65^{\circ} \mathrm{W}$ & 0.067 & 3.53 & 1.00 & 957 \\
\hline Azores $38^{\circ} \mathrm{N} 29^{\circ} \mathrm{W}$ & 0.064 & 2.82 & 1.39 & 761 \\
\hline \multicolumn{5}{|c|}{ Pacific Ocean } \\
\hline Nauru $0^{\circ} 167^{\circ} \mathrm{E}$ & 0.058 & 4.05 & 0.43 & 1653 \\
\hline Tahiti $17^{\circ} \mathrm{S} 150^{\circ} \mathrm{W}$ & 0.056 & 3.61 & 0.80 & 2104 \\
\hline Lanai $21^{\circ} \mathrm{N} 157^{\circ} \mathrm{W}$ & 0.049 & 3.23 & 0.69 & 6243 \\
\hline San Nicolas $33^{\circ} \mathrm{N} 119^{\circ} \mathrm{W}$ & 0.051 & 1.07 & 1.05 & 3734 \\
\hline \multicolumn{5}{|c|}{ Indian Ocean } \\
\hline Kaashidhoo $5^{\circ} \mathrm{N} 73^{\circ} \mathrm{E}$ & 0.100 & 4.69 & 1.11 & 400 \\
\hline \multicolumn{5}{|c|}{ Averages } \\
\hline Atlantic Ocean & 0.071 & 3.36 & 1.10 & 2765 \\
\hline Pacific Ocean & 0.052 & 2.80 & 0.77 & 13734 \\
\hline
\end{tabular}

The differences between the baseline aerosol in the Pacific, Atlantic and the one location in the Indian Oceans are significant. They can be due to differences in the meteorological conditions that change the strength of sources of the baseline aerosol, or due to possible remaining contamination of pollution/dust sources. In the Indian Ocean the baseline optical thickness was estimated using chemical analysis to be 0.07 for the visible [Ramanathan et al 2001]. It probably corresponds to a longer wavelength and thus is by 0.01-0.02 smaller than our estimate. Possible contamination of the baseline optical thickness is discussed in regard to Fig. 2 to 4 . The baseline optical thickness and average optical thickness for each site are plotted in Fig. 2 as a function of the total precipitable water vapor for the baseline conditions. The precipitable water vapor is an indication of the meteorological conditions in the site that determine the aerosol properties. Note that the difference between the average optical thickness and the derived baseline is much larger in the Atlantic and Indian sites than the Pacific sites. If we exclude the small number of points in the Cape Verde and Ascension Island (that have no significant influence on the weighted average used in Table 1) we get a very high nonlinear correlation of the baseline optical thickness to the precipitable water vapor. Additional insight into the differences between the locations is gained from the volume size distributions plotted in Fig. 3. The size distributions are derived from the sky radiance spectral-angular measurements [Dubovik and King, 2000; Dubovik et al. 2000]. All stations are characterized by accumulation and coarse modes. The volume of the accumulation mode is much larger for the Atlantic Ocean than for the Pacific Ocean. The parameters of a two lognormal fit to the size distribution are given in Table 2.

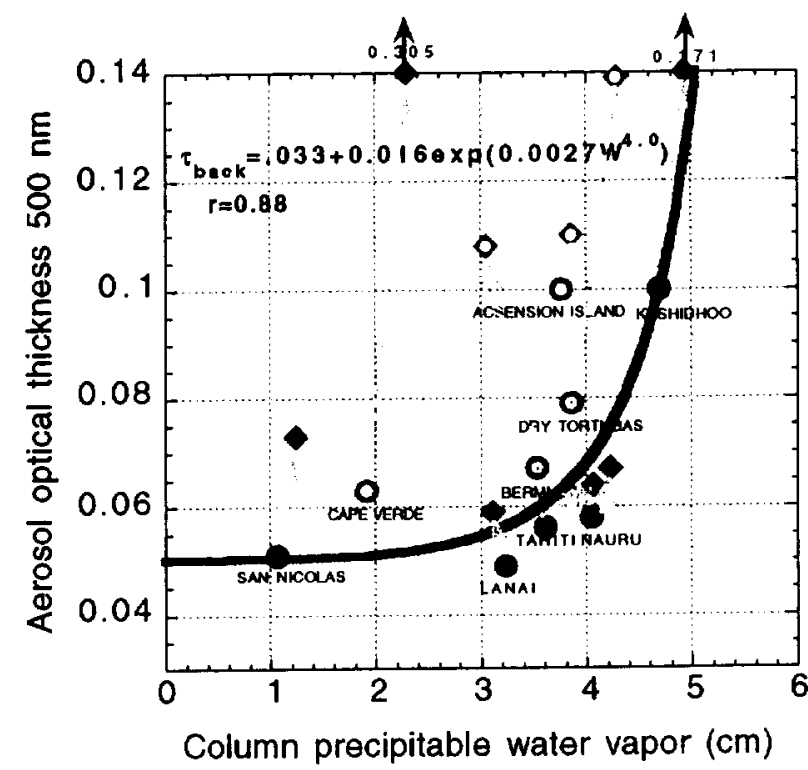

Figure 2: Baseline aerosol optical thickness for all the stations (green), and the average optical thickness for each station (red) as a function of the total precipitable water vapor in the baseline conditions. Pacific Ocean - blue squares and the Atlantic stations - white circles. The blue line is a fit to the baseline aerosol excluding Cape Verde and Ascension Island, due to the small number of identified medians $(<300)$. Data from Azores Island do not have yet the final calibration and are not included in the analysis.

\section{Fine vs. coarse mode aerosol}

Satellite measurements of aerosol can be used to distinguish between natural coarse particles and man-made fine aerosol. Therefore, the baseline spectral optical thickness is also 
separated into fine and coarse modes using the parameters in Table 2a. The optical thickness transitions from being dominated by fine particles for short wavelengths to being dominated by the coarse particles for the long wavelengths (Table $2 b$ ). For $\lambda=500 \mathrm{~nm}$ the contribution of the fine mode is higher for the Atlantic $\left(\tau_{a-f i n e} e^{0.045)}\right.$ than for the Pacific ( $\tau_{a-f i n e}-0.029$ ) oceans. The contributions of the coarse modes are similar (Atlantic -0.026 , Pacific -0.023 ), except of the strong coarse mode in Naru.

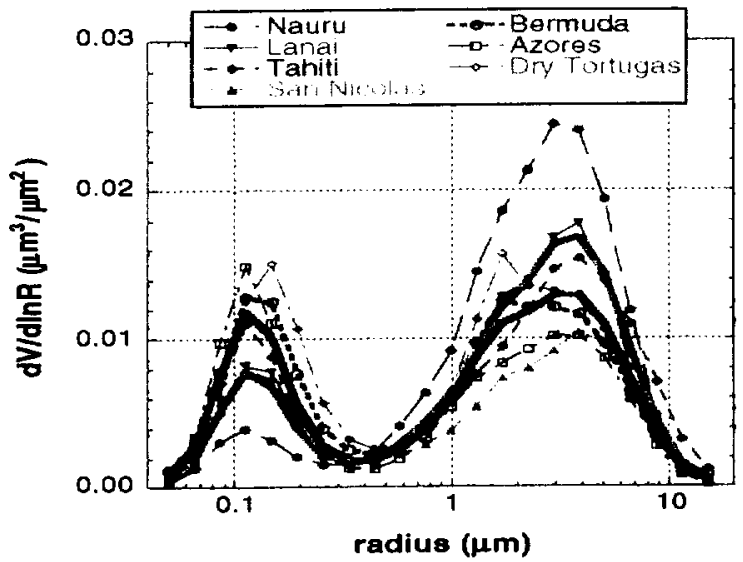

Figure 3: Aerosol volume size distribution (dV/dlnr) averaged for conditions that correspond to the baseline optical thickness in 4 Pacific sites and 3 Atlantic sites. The average size distribution for each ocean is given by the solid lines (blue for the Pacific, and orange for the Atlantic).

Table 2: (a) Size distribution parameters for the average baseline optical thickness over the Atlantic and Pacific Oceans. The size distribution is integrated from radius of 0.05 $\mu \mathrm{m}$ to $0.44 \mu \mathrm{m}$ for the fine mode and $0.44 \mu \mathrm{m}$ to $15 \mu \mathrm{m}$ for the coarse mode. $R_{v}$ is the volume geometric mean radius $(\mu \mathrm{m})$, $R_{e f f}$ is the effective radius $(\mu \mathrm{m}), \sigma$ is the geometric standard deviation, (b) The contribution of the fine and coarse modes to the spectral baseline optical thickness using the size information in (a) and refractive index of 1.35-0.001i.

(a) size distribution parameters

\begin{tabular}{|c|c|c|c|c|}
\hline \multirow[t]{2}{*}{ Parameter } & \multicolumn{2}{|c|}{ Atlantic Ocean } & \multicolumn{2}{|c|}{ Pacific Ocean } \\
\hline & Fine & Coarse & fine & Coarse \\
\hline $\mathrm{R}_{\mathrm{v}}(\mu \mathrm{m})$ & 0.14 & 2.49 & 0.13 & 2.94 \\
\hline $\mathrm{R}_{\mathrm{eff}}(\mu \mathrm{m})$ & 0.13 & 1.83 & 0.12 & 2.23 \\
\hline$\sigma$ & 0.42 & 0.78 & 0.43 & 0.74 \\
\hline $\begin{array}{l}\text { Number of particles in } \\
\text { the column }\left(\mathrm{cm}^{-2}\right) * 10^{6}\end{array}$ & 250 & 0.2 & 185 & 0.2 \\
\hline Volume $\left(\mu \mathrm{m}^{3} / \mathrm{cm}^{2}\right) * 10^{6}$ & 1.4 & 2.7 & 0.9 & 2.7 \\
\hline \multirow{2}{*}{\multicolumn{5}{|c|}{$\frac{\text { Number/Volume }(\mu \mathrm{m})}{(\mathrm{b}) \mathrm{spe}}$}} \\
\hline & & & & \\
\hline \multirow{2}{*}{$\begin{array}{l}\text { Wavelength } \\
(\mathrm{nm})\end{array}$} & \multicolumn{2}{|c|}{ Atlantic Ocean } & \multicolumn{2}{|c|}{ Pacific Ocean } \\
\hline & Fine & Coarse & Fine & Coarse \\
\hline 440 & 0.062 & 0.026 & 0.037 & 0.021 \\
\hline 500 & 0.047 & 0.027 & 0.027 & 0.021 \\
\hline 860 & 0.012 & 0.028 & 0.007 & 0.023 \\
\hline 1650 & 0.001 & 0.027 & 0.001 & 0.024 \\
\hline 2130 & 0.001 & 0.024 & 0.000 & 0.022 \\
\hline
\end{tabular}

The baseline size distributions can be integrated to calculate the number concentration of the particles for the baseline conditions (Table 2a). Since the maritime particles are expected to be hygroscopic, and the size distribution was derived for particles larger than $0.05 \mu \mathrm{m}$ radius, the number of particles should closely resemble the $\mathrm{CCN}$ concentration. The efficiency of the aerosol to serve as $\mathrm{CCN}$ is expressed by the ratio of the particle number to volume. This ratio, rather than the number itself is easier to compare with in situ measurements that report the concentrations per unit volume. The ratio of 167 for the Atlantic Ocean is similar to the ratio measured in situ from aircraft of $200 \pm 30$

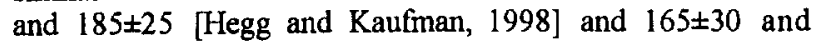
$168 \pm 70$ [Van Dingenen et al. (1999), and Hegg and Jonsson 2000].

\section{Seasonal cycle}

The procedure to derive the baseline aerosol is based on the availability of a large data set that can be used to extract the baseline conditions. Derivation of the seasonal trends is therefore less accurate. We divided the data set for each site to 3 months seasonal intervals, and average the seasonal baseline value for all the years for which the data is available. Fig. 4 shows the baseline value for the Pacific and Atlantic sites that have at least 9 months of data. The Pacific baseline shows a systematic increase in the Northem Hemisphere spring, associated with transport of Asian dust. The Atlantic data also peaks in the same period. This seasonal change does not indicate a significant seasonal cycle in the baseline aerosol.

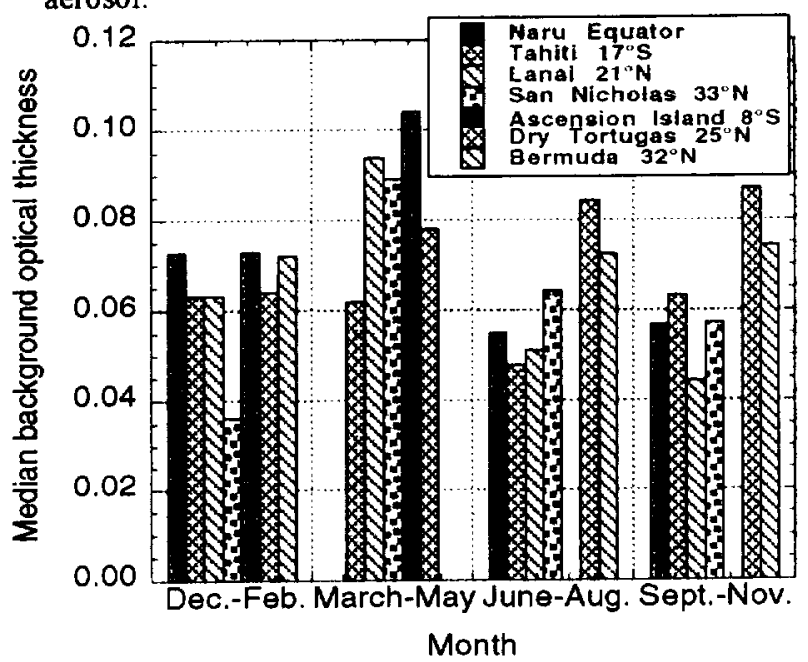

Figure 4: Seasonal variation of the baseline optical thickness for Pacific and Atlantic sites. Multiyear data sets were used. Data sets from locations and seasons with less than 70 baseline medians are not displayed. The higher baseline over the Northern Pacific is probably due to contamination by transport of Asian aerosol.

\section{Discussion and Conclusions}

Using several years of measurements in 10 stations of the Aerosol Robotic network (AERONET) we derived the optical thickness and properties of the baseline aerosol. The baseline aerosol optical thickness over the Pacific Ocean is 0.052 at $500 \mathrm{~nm}$ with Angstrom exponent of 0.77 , and 0.071 and 1.1 respectively over the Atlantic. The baseline aerosol is derived assuming that pollution or dust is 
significantly more heterogeneous than the baseline aerosol due to the restricted size of the source and variation of meteorological conditions responsible for generation and transport of the aerosol. The median is derived for periods of stable optical thickness (variation < 0.02) during 2-6 days of consecutive cloud free, 15 minute measurements. How well do we derive the baseline aerosol? Since we do not know the ultimate "true" baseline, we performed a sensitivity study (Fig. 6). A long term variation in the baseline aerosol is combined with short term variations in pollution optical thickness. On the simulated data set the same approach to find the baseline aerosol is applied. Despite the much stronger pollution sources, the methodology allows us to derive the baseline aerosol optical thickness within an error of 0.003 or 0.008 . Therefore, it is expected that the contamination of the baseline is between 0.00 and $\Delta \tau=+0.01$. Using size distribution measurements that correspond to the median conditions, the baseline aerosol is separated into fine and coarse modes. Satellite measurements of the aerosol optical thickness corresponding to the fine and coarse modes [e.g. MODIS: Tanré et al., 1997, 1999, Remer et al., 2001] can then be used to derive the man-made contribution (elevated fine mode) and natural coarse mode. This can be a step towards identifying our impact on the aerosol distribution and its forcing of climate.

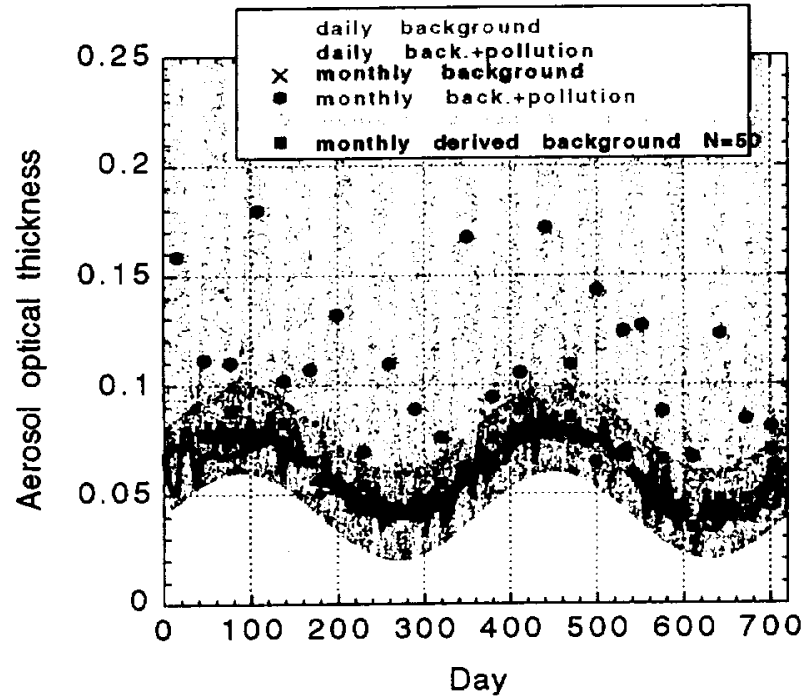

Fig. 6: Simulation of the method to derive the baseline aerosol optical thickness. A time series with a baseline aerosol (blue dots) in the form of an annual sinusiodal pattern and 5-15 days random sinusiodal variations is used: $\tau_{\text {baseline }}=0.02[2+\sin (\mathrm{D} \pi / 180)]+0.02\left[1+\sin \left(\mathrm{D} \pi /\left(5+10 \mathrm{R}_{\mathrm{AND}}\right)\right)\right]$; where $D$ is the day number. $R_{A N D}$ is a random number ( 0 to 1$)$. Pollution is added in a semi-random pattern every 24 days: $\tau_{\text {poll }}=0.15 \mathrm{R}_{\text {and }}[1+\sin (\pi \mathrm{D} / 24)]$ - red dots. The monthly median total optical thickness is shown by $(\bullet)$ and the median optical thickness for 50 and 100 point series with variation < 0.02 by $(\bullet)(\boldsymbol{\square})$. The baseline true median optical thickness of 0.060 was retrieved as 0.066 .

\section{References}

Dubovik, O., and M.D.King, A flexible inversion algorithm for retrieval of aerosol optical properties from sun and sky radiance measurements, J.Geophys.Res., 105, 20,673-20,696, 2000.
Dubovik, O., A.Smirnov, B.N.Holben, M.D.King, Y.J.Kaufman, T.F.Eck, and I.Slutsker, Accuracy assessments of aerosol optical properties retrieved from AERONET sun and sky radiance measurements, J.Geophys.Res., 105, 9791-9806, 2000.

Hansen, J., M. Sato and R. Ruedy, Radiative forcing and climate response, J. Geophys. Res., 102, 6831-6864, 1997.

Hegg, D.A. and Y.J.Kaufman, Measurements of the relationship between submicron aerosol number and volume concentration, $J$. Geophys. Res., 103, 5671-5678, 1998.

Hegg, D.A. and H.Jonsson, Aerosol number-to-volume relationship and relative humidity in the eastern Atlantic, J. Geophys. Res., 105, 1987-1995, 2000

Higurashi, A. and T. Nakajima, 1999: Development of a two channel aerosol retrieval algorithm on global scale using NOAA AVHRR. J. Atmos. Sci., 56, 924-941.

Holben, B. N., T. F. Eck, I. Slutsker, D. Tanre, et al.,, AERONET-A federated instrument network and data archive for aerosol characterization, Rem. Sens. Environ., 66, 1-16 (1998).

Holben, B.N., D. Tanre, A. Smirnov, T.F. Eck et al., An emerging ground based aerosol climatology: Aerosol optical depth from AERONET, J. Geoph. Res.,, 2001 (accepted, in press).

Husar, R. B. J. Prospero and L.L. Stowe, Patterns of tropospheric aerosols over the oceans, J. Geophys. Res. 102, 16,889 (1997).

Jankowiak I. and D. Tanré, 1992: Climatology of Saharan dust events observed from Meteosat imagery over Atlantic Ocean. Method and preliminary results, J. Clim., 5, 646-656.

Kaufman, Y. J., D. Tanré, H. R Gordon, T. Nakajima, et al., 1997b: Passive remote sensing of tropospheric aerosol and atmospheric correction, J. Geoph. Res., 102, 16815-16830.

Kiehl, J. T., and B. P. Briegleb, The relative roles of sulfate aerosols and greenhouse gases in climate forcing, Science, 260, 311-314, 1993 .

King, M. D., Y. J. Kaufman, D. Tanre, and T. Nakajima: Remote sensing of tropospheric aerosols from space: past, present and future. Bull. of Meteor. Soc.. 80, 2229-2259, 1999.

Mishchenko, M. I., I. V. Geogdzhayev, B. Cairns, W. B. Rossow, and A. A. Lacis, Aerosol retrievals over the ocean by use of channels 1 and 2 AVHRR data: sensitivity analysis and preliminary results, Appl. Opt. 38, 7325-7341, 1999.

Ramanathan, V., P. J. Crutzen, J. Lelieveld et al., The Indian Ocean Experiment: An assessment of the climate forcing and effects of the great Indo-Asian haze, submitted to J. Geophys. Res., 2001

Remer, L. A., D. Tanre, Y. J. Kaufman, C. Ichoku, S. Mattoo, R. Levy, D. A. Chu, B. N. Holben, J. V. Martins, and R.-R. Li and Z. Ahmad, Validation of MODIS Aerosol Retrieval Over Ocean, submitted to GRL

Smirnov, A., B.N.Holben, T.F.Eck, O.Dubovik, and I.Slutsker, Cloud screening and quality control algorithms for the AERONET data base, Rem. Sens. Env., 73, 337-349. 2000.

Smirnov, A., B.N.Holben, Y.J.Kaufman, O.Dubovik, T.F.Eck, I.Slutsker, C.Pietras, and R.Halthore, Optical properties of atmospheric aerosol in maritime environments, J.Atm.Sci., 2001 (submitted).

Tanré, D., Y. J. Kaufman, M. Herman and S. Mattoo, 1997: Remote sensing of aerosol over oceans from EOS-MODIS. JGRAtmospheres, special issue on remote sensing of aerosol and atmospheric corrections, 102, 16971-16988.

Tanré, D., L.R. Remer, Y.J. Kaufman, P.V. Hobbs, J.M. Livingston, P.B. Russel, A. Smirnov, 1999: Retrieval of Aerosol Optical Thickness and Size Distribution Over Ocean from the MODIS Airborne Simulator during Tarfox, J. Geophys. Res, 104, 22612278.

Tegen I., A.A. Lacis and I. Fung, The influence on climate forcing of mineral aerosols from disturbed soils, Nature, 380,419-422, 1996.

Van Dingenen, R., F.Raes, J.-Ph.Putaud, A.Virkkula, and M.Mangoni, Processes determining the relationship between aerosol number and non-sea-salt sulfate mass concentratons in the clean and perturbed marine boundary layer, J. Geophys. Res., 104, 8027$8038,1999$.

Yoram J. Kaufman and Brent N. Holben are in NASAVGSFC code 913 and 923 respectively, Greenbelt MD 20771 (kaufman@climate.gsfc,nasa.goy).

Alexander Smimov and Oleg Dubovik are in Science Systems and Applications, Inc., Lanham, MD 20706 